\title{
Economic growth forecasting apparatus in regions with different reproduction structure
}

\author{
Yulia Vetakova $^{1,{ }^{*}}$ and Irina Bulgakova ${ }^{2}$ \\ ${ }^{1}$ Southwest State University, 305004, 94, 50 Let Oktyabrya str., Kursk, Russia \\ ${ }^{2}$ Voronezh State University, 394018, 1, Universitetskaya pl., Voronezh, Russia
}

\begin{abstract}
Identifying the main factors of economic growth, the study and analysis of the mechanisms of their influence on the development of regions can be considered one of the most pressing problems in modern economic research. The main goal of the research is to build an econometric production model of regional economic growth on the basis of an analysis of existing analytical approaches to assessing regional economic growth. To achieve this goal, a study was conducted to assess the quality of economic growth using multiplicative models of production functions by regions of the Russian Federation, which will allow building a unique function for each region, which describes the economic potential and the future direction of regional development. As a result of the study, it was concluded that it is necessary to adjust the existing and develop new approaches to assessing the dynamics of economic development. An econometric production model of regional economic growth is presented, which is based on production functions.
\end{abstract}

\section{Introduction}

Determining directions, factors and conditions for sustainable growth of the regional economy requires the development of appropriate forecasting and analytical tools that would allow the authorities of the constituent entity of the Russian Federation to carry out scientifically based forecasts of the consequences of management decisions made, to carry out multivariate scenario studies of economic growth opportunities, including scenarios of the Ministry of Economic Development in the framework of the annual forecasts of the socioeconomic development of the Russian Federation. The core of such tools should be an economic and mathematical model of economic growth in the region, which would make it possible in the medium and long term to assess the limits of growth in gross output and gross regional product depending on investment efforts, effective demand, demographic factors, environmental behaviour, and rates technical progress and other aspects of sustainable growth. The analysis of existing in the literature approaches to the study of problems of modelling and forecasting economic growth allows us to identify the following main directions. The main category of models, which is based on the description and analysis of regional economic systems, are econometric models. In the scientific literature there are many different types and classes of economic growth models based on production functions

\footnotetext{
*Corresponding author: vertakova7@ya.ru
} 
that differ in the depth of the description of the object of modeling, the methods of construction and the scope. They are classically the regression equations of the link between exogenous (basic models of J.M. Keynes [1], R. Harrod [2], E. Domar [3], R. Solow [4] and endogenous variables x (G. Mankiw, D. Romer, D. Weil [5], R. Lucas [6], K. Arrow [7], P. Romer [8], F. Aghion and P. Hauitta [9]). Modeling of economic growth on inter-sector models goes back to the models of expanded reproduction of K. Marx. The approach to modeling economic growth on the basis of the inter-sectoral balance of V. Leontiev is based on the description of the product and financial flows between sectors of the economy with the link between supply and demand.

The study was based on works of such famous economists as S. Kuznets [10], A. Aganbegyan [11], L. Gardini [12], Y. Vertakova [13], V. Plotnikov [14] and others.

The conducted study suggests that the process of choosing the analytical form of dependencies is based on time and space series using statistical methods.

\section{Materials and Methods}

The most frequently used and studied in economic analysis is the Cobb-Douglas function. It was this function that R. Solow used in his theory of economic growth [4], modifying it and adapting it to the complex nature of economic systems. If the Cobb - Douglas model was based on only two basic factors - labor and capital - then R. Solow introduced the third factor, which takes into account technical progress. The model is described by a multiplicative production function, includes the influence of the three factors mentioned on economic growth and has a number of conditions and limitations:

$$
Y=A K^{\alpha_{1}} L^{\alpha_{2}}, \alpha_{1}, \alpha_{2}>0
$$

where $\mathrm{Y}$ is the volume of release;

A - factor taking into account the impact of technical progress (the remainder of Solow);

$\mathrm{K}$ - capital costs;

$\mathrm{L}$ - labor costs;

$\alpha_{1}, \alpha_{2}$ - parameters of the production function.

Technical progress in model (1) means all qualitative changes in labor and capital. The entered parameter A shows the cumulative effect of all factors not reflected in labor and capital (methods of organizing production, type of ownership, economic structure, state of the economy in the long term, etc.).

The considered production function in its classical form, region a, gives the so-called unit scale effect or constant returns to scale, which is expressed as $\alpha_{1}+\alpha_{2}=1$. This means that with an increase in production factors of $1 \%$, we obtain the same increase in the result. In the real construction and subsequent studies of function (1) there are significant difficulties. The main problem of the practical implementation of such a function is caused by the difficulty in identifying its effective feature and the argument factors necessary for carrying out the calculations. Measuring factor $\mathrm{L}$ is not difficult if one takes into account its simplified interpretation as the number of people employed in the economy. In (1), the quality of human capital, the level and quality of education, the factors influencing the health status of labor resources, the age composition of resources and their gender characteristics are not taken into account. However, in most studies, these characteristics are not given due attention or no attention at all $[7,13]$. Certain difficulties also arise when measuring in comparable prices the region's GDP or GRP over a number of years. For example, it is not possible to determine the nature of the impact of the innovation component on the change in GRP, to represent in numerical terms the impact of scientific and technological progress, to identify the relationship between the cost of innovation and the dynamics of economic growth in the region. When using separate regression equations, it is assumed that the arguments can be 
changed independently of each other. But, as is well known, the change of one variable, as a rule, cannot occur with the absolute immutability of others. Additional investment has an impact on labor, the size of the GRP affects innovation, but innovation also influences GRP. Consequently, a separately taken regression equation as an econometric model cannot characterize the true relationship of individual features.

Here it is necessary to note the approach of A. Arzhenovsky and S. Arzhenovsky [2], proposing to use the system of simultaneous econometric equations as a model of economic growth:

$$
\left\{\begin{array}{c}
Y_{1_{t}}=\beta_{0} Y_{2_{t}}^{\beta_{1}} X_{1_{t}}^{\beta_{2}} X_{2_{t}}^{\beta_{3}} \varepsilon_{1_{t}} \\
Y_{2_{t}}=\alpha_{0} Y_{1_{t}}^{\alpha_{1}} X_{2_{t}}^{\alpha_{2}} X_{3_{t}}^{\alpha_{3}} X_{4_{t}}^{\alpha_{4}} \varepsilon_{2_{t}}
\end{array},\right.
$$

where $Y_{1 t}-$ gross regional product in the period $t$;

$\mathrm{Y}_{2 \mathrm{t}}$ - the cost of technological innovation in the period $\mathrm{t}$;

$\mathrm{X}_{1 \mathrm{t}}$ - the number of people employed in the region during period $\mathrm{t}$;

$\mathrm{X}_{2 \mathrm{t}}$ - the value of fixed assets of the regional economy in the period $t$;

$\mathrm{X}_{3 \mathrm{t}}-$ the number of personnel engaged in scientific research in the period $\mathrm{t}$;

$\mathrm{X}_{4 \mathrm{t}}$ - the average per capita income of the population in the period $\mathrm{t}$;

$\beta 0, \beta 1, \beta 2, \beta 3, \alpha 0, \alpha 1, \alpha 2, \alpha 3, \alpha 4$ are the parameters of the production function;

$\varepsilon_{1 \mathrm{t}}, \varepsilon_{2 \mathrm{t}}$-random variable characterizing the deviation of the real value of the resultant trait from the theoretical value found using the regression equation.

Although the set of independent factors in the model (2) raises certain questions and is debatable, the solution of such a system can be found quite simply, and absolute data can be used as initial data.

Analysis of the current state of the theory and practice of modeling and forecasting economic growth allows us to draw conclusions about the need to adjust the existing and develop new models to take into account a number of current trends in economic development.

\section{Results}

In the most general form, two basic types of regional econometric models can be distinguished, differing in the level of complexity of approximated relationships - aggregated and disaggregated (Figure 1).

As practice shows, the choice of endogenous factors, reflecting the effectiveness of the development of regional economic systems, and the identification of factors contributing to the change in the target states of the studied systems are not the main conditions for successfully solving the problem of modeling the growth trajectory.

Obtaining econometric models for assessing economic dynamics with a high level of adequacy is possible only when in the economic space, which is mostly heterogeneous, typology of the studied systems is carried out and the regional groups that are homogeneous in the reproduction mechanism are classified in a special way [1]. Such a classification is possible with the use of the apparatus of production functions. 


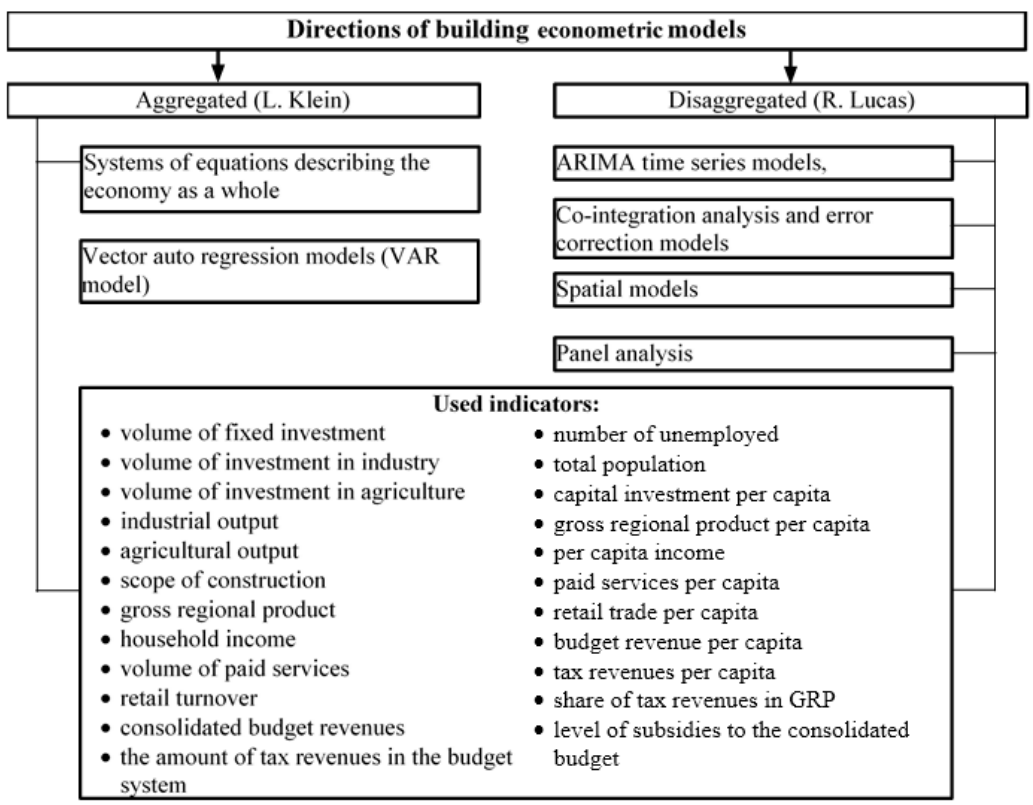

Fig. 1. The main classification of regional econometric models. Compiled by the authors.

We believe that solutions to the problems of modeling and forecasting economic growth can be proposed using the class of hybrid models. A similar class of models is reflected in $[4,5]$. Its characteristic feature is the possibility of constructing a certain integral indicator of economic growth, as the convolution of basic production functions, which are considered equivalent.

The model of economic growth of gross regional product (GRP) is represented by some function in time $t$, depending on production factors:

$$
G R P(t)=Y(L(t), K(t), A(t)),
$$

where L ( $\mathrm{t}$ ) - labor resources of the region, taking into account their quality (for example, human capital can be measured by the average duration of training);

$\mathrm{K}(\mathrm{t})$ - accumulated in capital (fixed assets);

A ( $\mathrm{t}$ - - the cumulative factor productivity (the impact of scientific and technological progress on labor productivity).

As growth functions $Y(L(t), K(t), A(t))$, we will consider the complementary production function of E. Denison (4) and the production function with constant elasticity of substitution (CES-function) (5):

$$
\begin{aligned}
& Y(t)=A(t) K^{\alpha}(t) L^{1-\alpha}(t) H^{1-\alpha}(t), \\
& Y(t)=\gamma\left[\delta K^{-\rho}(\mathrm{t})-(1-\delta) L^{-\rho}(t)\right]^{-\frac{\vartheta}{\rho}} .
\end{aligned}
$$

Using the model of E. Denison allows to take into account the quality index of labor $\mathrm{H}(\mathrm{t})$, calculated on the basis of educational categories of the working population, taking into account the average wage. The use of the CES function makes it possible to avoid the drawbacks that are inherent in the Cobb-Douglas function, namely, there is no improbable replacement of one factor by another with an unlimited increase in labor productivity.

The following parameters are used in models (4) and (5): $\alpha$ is the elasticity of capital, or (1- $\alpha$ ) is the elasticity of labor, $\gamma \geq 0$ determines productivity, $0 \leq \delta \leq 1$ - optimal distribution of 
production factors, $v \geq 0$ - elasticity scale, the parameter $\rho \geq-1$ is related to the elasticity of the replacement.

To determine the parameters of the function (4), it is necessary to use the standard approach - to carry out its linearization. In this case, the linear regression model best approximates the empirical data. The model of E. Denison used by us is fairly easily reduced to a linear form by the procedure of the classical logarithmic procedure. The result for functions (4) is the equation:

$$
\ln Y(t)=\ln A(t)+\alpha \ln K(t)+(1-\alpha) L(t)+(1-\alpha) H(t),
$$

Equation (6) is much simpler if you initially carry out transformations of the original function:

$$
Y(t)=A(t) K^{\alpha}(t) \frac{L(t)}{L^{\alpha}(t)} \frac{H(t)}{H^{\alpha}(t)}=A(t)\left(\frac{K(t)}{L(t) H(t)}\right)^{\alpha} L(t) H(t)
$$

This transition allows you to bring function (4) to a single-factor regression model:

$$
\ln Y(t)=\ln A(t)+\alpha \ln \left(\frac{K(t)}{L(t) H(t)}\right)+\ln (L(t) H(t)) .
$$

Parameters (8) are determined using the least squares method.

The statistics used to build the model are shown in Table 1 and Table 2.

Table 1. Statistics for the Voronezh region.

\begin{tabular}{|c|c|c|c|c|c|c|c|}
\hline Year & GRP $(\mathrm{t})$ & $\mathrm{L}(\mathrm{t})$ & $\mathrm{H}(\mathrm{t})$ & $\mathrm{K}(\mathrm{t})$ & $\mathrm{I}(\mathrm{t})$ & $\mathrm{R}(\mathrm{t})$ & $\mathrm{B}(\mathrm{t})$ \\
\hline 2010 & 346568.2 & 1124 & 14337.3 & 125826 & 13431.8 & 13.184 & 71235.3 \\
\hline 2011 & 474973.9 & 1133 & 16054.7 & 155245 & 13431.8 & 14.106 & 77324.1 \\
\hline 2012 & 563965.4 & 1164 & 19538.1 & 182334 & 16169.4 & 10.799 & 87607.5 \\
\hline 2013 & 611720.4 & 1154 & 21825.2 & 216983 & 13520.8 & 10.763 & 91499.7 \\
\hline 2014 & 717667.2 & 1161 & 24000.7 & 243260 & 24742.4 & 10.865 & 93594 \\
\hline 2015 & 805969.6 & 1162 & 24905.9 & 264660 & 50120.6 & 10.600 & 98442.2 \\
\hline 2016 & 841375.7 & 1165 & 26335.2 & 270999 & 27123.6 & 10.334 & 105614.8 \\
\hline
\end{tabular}

Compiled by the authors based on http://www.gks.ru/free_doc/new_site/bd_munst/munst.htm

Table 2. Statistics for the Kursk region.

\begin{tabular}{|c|r|c|c|c|c|c|c|}
\hline Year & GRP $(\mathrm{t})$ & $\mathrm{L}(\mathrm{t})$ & $\mathrm{H}(\mathrm{t})$ & $\mathrm{K}(\mathrm{t})$ & $\mathrm{I}(\mathrm{t})$ & $\mathrm{R}(\mathrm{t})$ & $\mathrm{B}(\mathrm{t})$ \\
\hline 2010 & 193648.6 & 589 & 14006.5 & 46093 & 1007.7 & 2.944 & 41966.4 \\
\hline 2011 & 228851.4 & 582 & 16240.8 & 58521 & 1007.7 & 3.128 & 41966.4 \\
\hline 2012 & 248213.1 & 566 & 18690.0 & 66639 & 6364.0 & 3.018 & 45233.0 \\
\hline 2013 & 271542.5 & 575 & 21234.2 & 71546 & 8591.3 & 3.016 & 47182.3 \\
\hline 2014 & 298287.3 & 571 & 23098.5 & 71743 & 13363.3 & 2.984 & 46780.6 \\
\hline 2015 & 336999.4 & 571 & 23921.4 & 73745 & 15087.2 & 2.891 & 51394.9 \\
\hline 2016 & 364601.7 & 570 & 25326.6 & 89662 & 24698.8 & 2.846 & 52673.1 \\
\hline
\end{tabular}

Compiled by the authors based on http://www.gks.ru/free_doc/new_site/bd_munst/munst.htm

Table 3 presents the data of calculations of the model E. Denison for the Voronezh and Kursk regions. 
Table 3. Comparative values of factors of E. Denison's model.

\begin{tabular}{|c|c|c|c|c|c|c|c|c|c|c|}
\hline \multirow[b]{2}{*}{ 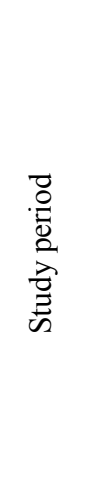 } & \multicolumn{5}{|c|}{ Voronezh region } & \multicolumn{5}{|c|}{ Kursk region } \\
\hline & $\alpha$ & $1-\alpha$ & 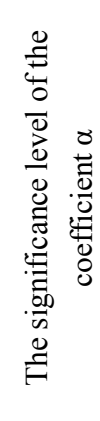 & 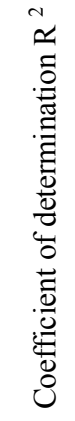 & 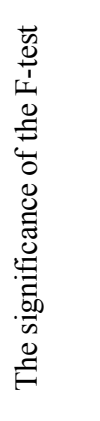 & $\alpha$ & $1-\alpha$ & 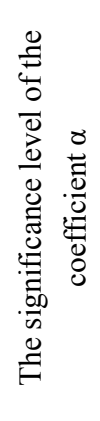 & 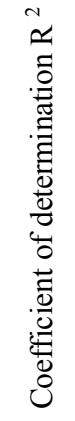 & 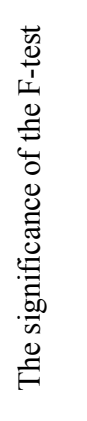 \\
\hline $\begin{array}{c}2010- \\
2016\end{array}$ & 1.35 & $\begin{array}{c}- \\
0.35\end{array}$ & 0.993 & 0.78 & 0,007 & 0.77 & 0.23 & 0.982 & 0.71 & 0,018 \\
\hline
\end{tabular}

Compiled by the authors based on http://www.gks.ru/free_doc/new_site/bd_munst/munst.htm

\section{Discussion}

It can be seen that in the compared regions, the gross regional product is more influenced by capital than labor costs and its quality. Note that in the Voronezh region, the cumulative increase in labor costs and the improvement of its quality by $1 \%$ of the average value will lead to a decrease in GRP by $0.35 \%$. Both models constructed explain a large percentage of the variation of the dependent variable, that is, the regression models are sufficiently qualitative. Small $p$ values for the F-test $(p<0.05)$ indicate that the hypothesis that there is no linear relationship between the variables should be rejected.

\section{Conclusions}

In our opinion, the solution to the problem of modeling and forecasting economic growth is an econometric production model of regional economic growth, built using a class of hybrid models. Its characteristic feature is the possibility of constructing a certain integral indicator of economic growth as a convolution of basic production functions, which are considered equivalent. The developed econometric production model of regional economic growth is universal and will allow for each region to build a unique function that describes the economic potential and the future direction of regional development.

\section{Acknowledgment}

This paper is an output of the science project of the government task of Ministry of education and science of the Russian Federation № 26.3546.2017/PCH "Development fundamentals of analysis and prediction of structural and dynamic parameters of the regional economy are based on the integration of the Russian and world experience of management of territorial development and modern scientific doctrines". 


\section{References}

1. J.M. Keynes, The General Theory of Employment, Interest, and Money (1997)

2. R.F. Harrod, Economic Journal 49(193), 14-33 (1939) doi:10.2307/2225181

3. E.D. Domar, Econometrica 14(2), 137-147 (1946) doi:10.2307/1905364

4. R.M. Solow, Quarterly Journal of Economics 70(1), 65-94 (1956) doi:10.2307/1884513

5. G. Mankiw, D. Romer, D. Weil, The Quarterly Journal of Economics 107(2), 407-437 (1992) doi: $10.2307 / 2118477$

6. R. Lucas, Econometrica 61(2), 251-272 (1993) doi:10.2307/2951551

7. K.J. Arrow, Review of Economic Studies 29(3) (1962) doi:10.2307/2295952

8. P. Romer, Journal of Political Economy 98(5), 71-102 (1990) doi:10.1086/261725

9. P. Aghion, P. Howitt, Econometrica 60(2), 323-351 (1992) doi:10.3386/w3223

10. S. Kuznets, The Theory and Experience of Economic Development Essays in Honour of Sir Arthur Lewis, 43-59 (2012) doi:10.4324/9780203838518

11. A.G. Aganbegyan, Studies on Russian Economic Development 25(4), 319-328 (2014) doi:10.1134/S1075700714040029

12. L. Gardini, L. Gori, L. Guerrini, M. Sodini, Chaos 28(5) (2018) doi:10.1063/1.5039304

13. Y. Vertakova, M. Klevtsova, T. Babich, Economic Annals-XXI 157(3-4), 4-7 (2016) doi:10.21003/ea.V157-0001

14. V. Plotnikov, Y. Vertakova, N. Moroz, Proceedings of the 31 st International Business Information Management Association Conference (IBIMA) "Innovation Management and Education Excellence through Vision", 1588-1596 (2018) 